\section{Case Reports in Ophthalmology}

Case Rep Ophthalmol 2020;11:287-292

DOI: 10.1159/000508065

Published online: July 6, 2020
(C) 2020 The Author(s)

Published by S. Karger AG, Basel www.karger.com/cop

This article is licensed under the Creative Commons Attribution-NonCommercial 4.0 International License (CC BY-NC) (http://www.karger.com/Services/OpenAccessLicense). Usage and distribution for commercial purposes requires written permission.

\title{
Apolipoprotein Al-Derived Vitreous Amyloidosis: An Elusive Diagnosis
}

\author{
Juan B. Yepez ${ }^{a}$ Felipe A. Murati ${ }^{a} \quad$ Michele Petitto $^{b}$ Jazmin De Yepez \\ Jose M. Galue ${ }^{a}$ Susana Vinardell ${ }^{d}$ Marco Mura $^{e} \quad$ J. Fernando Arevalo ${ }^{f}$ \\ aVitreoretinal Surgery Department, Clinica de Ojos, Maracaibo, Venezuela; \\ ${ }^{b}$ Glaucoma Department, Clinica de Ojos, Maracaibo, Venezuela; 'Pediatric and Strabismus \\ Department, Clinica de Ojos, Maracaibo, Venezuela; dRetina Department, Sotero del Rio

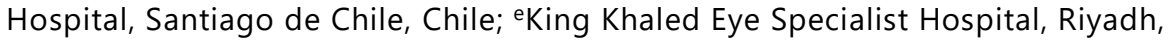

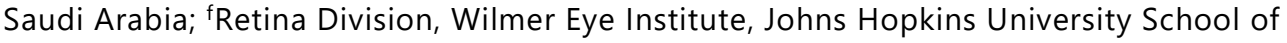 \\ Medicine, Baltimore, MD, USA
}

\section{Keywords}

Amyloid · Amyloidosis · Vitreous opacity · Vitrectomy · Pars plana vitrectomy

\begin{abstract}
A 56-year-old female presented with vitreous opacity with gradual visual disturbance in her right eye of 1-year duration. A Non-Hodgkin's lymphoma had been treated 15 years before. Presenting best-corrected visual acuity (BCVA) was 20/200 in her right eye and 20/25 in her left eye. Intraocular pressure was $18 \mathrm{~mm} \mathrm{Hg}$ bilaterally. Slit-lamp examination revealed no abnormal findings in the anterior segment of both eyes, including the absence of cells and flare. Fundoscopic examination indicated hazy media with the typical glass-wool-like appearance in her right eye. B-scan ultrasound demonstrated that the vitreous was full of middle-echo spots, vitreous opacities, and posterior vitreous detachment occurred. The patient underwent vitreous biopsy and a standard 25-gauge pars plana vitrectomy (diagnostic and therapeutic). Intraoperatively, the eye was noted to have severe diffuse debris and very strong vitreoretinal adhesions. Cytospin smears prepared from the vitreous aspirate indicated amorphous acellular material that stained positively with Congo Red and showed apple green birefringence on polarized microscopy, consistent with the diagnosis of amyloidosis. A genetic evaluation of tongue tissue demonstrated apolipoprotein Al-derived amyloidosis. The BCVA was 20/25 OU at 3 months postoperatively.




\section{Case Reports in Ophthalmology}

\section{Introduction}

Amyloidosis refers to a rare group of diseases characterized by extracellular deposition of amyloid, a fibrillar material derived from various precursor proteins that self-assemble with highly ordered abnormal cross $\beta$-sheet conformation [1, 2]. Deposition of amyloid can occur in the presence of an abnormal protein (e.g., hereditary amyloidosis and acquired systemic immunoglobulin light chain amyloidosis), in association with prolonged excess abundance of a normal protein (e.g., reactive systemic amyloidosis and $\beta 2$-microglobulin dialysisrelated amyloidosis), and, for reasons unknown, accompanying the ageing process (e.g., wildtype transthyretin amyloidosis, or senile systemic amyloidosis and atrial natriuretic peptide amyloidosis) [3].

Ocular manifestations are observed in only $10 \%$ of the cases of familial amyloidosis polyneuropathy [4]. The incidence of vitreous opacities in familial amyloidosis polyneuropathy varies from 5.4 to $35 \%$. [4, 5]. Vitreous amyloidosis is almost always related to mutant transthyretin, which is a plasma protein carrier of thyroxine and vitamin [5].

The case report presents a patient with persistent vitreous opacity in amyloidosis, and we confirm the difficultly in diagnosing some of these cases based on their clinical features alone.

\section{Case Presentation}

A 56-year-old female presented to the clinic on May 23, 2019, with gradual visual disturbance in her right eye of 1-year duration for a second opinion. The patient was prescribed nonsteroidal and steroidal eye drops for a "nonspecific uveitis" for 3-6 months before presentation, without any improvement. A Non-Hodgkin's lymphoma had been diagnosed and treated 15 years before and was in remission without further treatment. Her family history was unremarkable, and she denied diabetes, hypertension, connective tissue disease, tuberculosis, hematologic disease, or cardiovascular disease. She also stated that she was not taking any oral medication. On initial examination, best-corrected visual acuity (BCVA) was 20/200 in her right eye and 20/25 in her left eye. Intraocular pressure was $18 \mathrm{~mm}$ Hg bilaterally. Slitlamp examination of the anterior segment was within normal limits bilaterally, including the absence of cells and flare. On fundoscopy, the media was hazy with the typical glass-wool-like appearance her right eye (Fig. 1). B-scan ultrasound indicated that the vitreous was full of middle-echo spots, vitreous opacities, and posterior vitreous detachment occurred (Fig. 2). The patient underwent vitreous biopsy and a standard 25-gauge pars plana vitrectomy (diagnostic and therapeutic PPV). Intraoperatively, severe diffuse debris was noted along with very strong vitreoretinal adhesions. A mechanical surgical posterior vitreous detachment was difficult. The diseased vitreous was very "gummy," adherent to the retina, and resistant to separation from the retina and was removed as thoroughly as possible. Vitreous samples were sent for histopathologic evaluation. The cytospin smears prepared from the vitreous aspirate revealed amorphous acellular material that stained positively with Congo Red and showed apple green birefringence on polarized microscopy (Fig. 3). These features were consistent with the diagnosis of amyloidosis. A genetic evaluation on tongue tissue demonstrated apolipoprotein AI-derived amyloidosis. The right eye underwent an additional PPV to remove residual vitreous that was difficult to remove during the first procedure due to the strong adhesion and "gummy" and adherent characteristics mentioned previously. Intravitreal triamcinolone was used to stain the vitreous during the second PPV. At the 3-month follow-up, the BCVA was 


\section{Case Reports in Ophthalmology}

$20 / 25$ OU. Six months later, there was no recurrence. No perivascular deposits were seen during the vitrectomies or the follow-up period. The patient was transferred to the internal medicine service for further evaluation and follow-up.

\section{Discussion and Conclusion}

In this report, we describe a female with unilateral gradually progressive visual disturbance with no anterior segment involvement and severe vitreous compromise and a persistent diffuse opacity treated with PPV. The differential diagnosis of vitreous opacities include degenerative, inflammatory, infectious, and hemorrhagic diseases. Vitreous cells can be associated with intraocular inflammation and opacity in the inferior vitreous. In our case, the vitreous had a uniform glass-wool-like appearance and had no signs of inflammation. Dehemoglobinized vitreous hemorrhage is similarly white. Asteroid hyalosis is a common cause of degenerative vitreous opacity. It usually presents in elderly patients [6]. However, it rarely causes visual disturbances.

Primary intraocular lymphoma had to be considered in our patient due to Non-Hodgkin's lymphoma treated 15 years before, as primary intraocular lymphoma may also lead to vitreous opacity [7]. Li et al. [8] described a patient presenting with primary vitreous retinal lymphoma with blurred vision unilaterally and floaters for 2 years with vitreous hemorrhage and an indiscernible fundus. Williams et al. [9] reported the presence of prominent granular crystalline clumps on intraocular lenses, the lens capsule, and iris [9] that could be present in amyloidosis. Hitchings and Tripathi [10] described multiple circumscribed grayish-white opacities on the posterior surface of the lens from which an opaque fibril ran posteriorly through a relatively clear zone to join a meshwork of vitreous opacities. Doft et al. [11] reported that these "footplates" of attachment of vitreous to the posterior surface of the lens occurred in approximately half of a group of eyes that underwent vitrectomy for vitreous amyloidosis and noted that this appearance may be useful in diagnosis.

In our case, Whipple's disease was considered. Whipple's disease is very rare with an estimated incidence of under $0.1 / 100,000 /$ year [12]. The classical symptoms involve the gastrointestinal tract, and severe weight loss is pathognomonic and also well known to be a rare cause of endocarditis. It is now known that Whipple's disease can involve many different organs, including the central nervous system [12]. Ocular involvement has been described with diffuse vitreous opacity [13]. However, our patient denied any severe weight loss prior to presentation, and no gastrointestinal symptoms occurred.

Vitreous amyloidosis is usually bilateral and asymmetrical [14]. Seca et al. [15] reported a case with unilateral vitreous opacities. We elected to perform vitrectomy because it is a reasonable and safe option to alleviate ocular morbidity in cases of vitreous amyloidosis [14]. In our case, peripheral and retrolental vitreous was carefully removed. One of the largest series of pars plana vitrectomies performed in 30 eyes with vitreous amyloidosis reported that reopacification of retrolental residual vitreous was the most common reason for repeat vitrectomy [14]. A series of pars plana vitrectomies performed in 30 eyes with vitreous amyloidosis indicated that reopacification and residual vitreous was the most common reason for a second vitrectomy [11]. In the current case, we did not observe any recurrence of amyloid in the vitreous over 6 months of follow-up.

In similar cases, close observation for glaucoma is advised because it can develop even years later, and uncontrolled cases can experience a rapid deterioration in vision [14]. Postoperative complications of vitrectomies for vitreous amyloidosis include secondary glaucoma, 


\section{Case Reports in Ophthalmology}

\begin{tabular}{l|l}
\hline DOI: $10.1159 / 000508065$ & (c) 2020 The Author(s). Published by S. Karger AG, Basel
\end{tabular} www.karger.com/cop

Yepez et al.: Apolipoprotein Al-Derived Vitreous Amyloidosis: An Elusive Diagnosis

vascular occlusions, and neovascularization $[14,16]$. However, there were no adverse events or postoperative complications in the current case.

In summary, this report presents a case of persistent vitreous opacity in amyloidosis and serves as a reminder that diagnosis based on clinical presentation alone can be quite challenging in some cases. In our case, the vision improved significantly after PPV, and there were no postoperative sequelae for the duration of 6 months of follow-up. However, regular long-term monitoring is required to assess for recurrence and secondary glaucoma.

\section{Statement of Ethics}

This study adhered to the tenets of the World Medical Association Declaration of Helsinki. The patient gave written informed consent to publish her case (including publication of images). Ethics board approval was not required for this study (Wilmer Eye Institute).

\section{Disclosure Statement}

The authors have no conflicts of interest to declare.

\section{Funding Sources}

The authors did not receive any funding.

\section{Author Contributions}

J.F.A., J.B.Y., and F.A.M. were involved in the conception and design of the paper and the analysis and interpretation of data; M.P., J.D.Y. acquired the data; J.M.G., S.V., M.M. interpreted the data; J.F.A., M.M., Y.B.Y. drafted the paper. All authors critically revised the paper and approved the final version of the paper submitted for publication. All authors agree to be accountable for all aspects of the work in ensuring that questions related to the accuracy or integrity of any part of the work are appropriately investigated and resolved.

\section{References}

1 Lachmann HJ, Hawkins PN. Systemic amyloidosis. Curr Opin Pharmacol. 2006 Apr;6(2):214-20.

2 Merlini G. Systemic amyloidosis: are we moving ahead? Neth J Med. 2004 Apr;62(4):104-5.

3 Sipe JD, Benson MD, Buxbaum JN, Ikeda S, Merlini G, Saraiva MJ, et al. Nomenclature 2014: amyloid fibril proteins and clinical classification of the amyloidosis. Amyloid. 2014 Dec;21(4):221-4.

4 Martins AC, Rosa AM, Costa E, Tavares C, Quadrado MJ, Murta JN. Ocular manifestations and therapeutic options in patients with familial amyloid polyneuropathy: a systematic review. BioMed Res Int. 2015;2015:282405.

5 Hashemian H, Jabbarvand M, Khodaparast M, Khalilipour E, Esfehani HR, Feng D, et al. Ocular presentations of amyloidosis. [Cited November 3, 2019]. Available from:

http://www.intechopen.com/books/amyloidosis/ocular-presentations-of-amyloidosis https://doi.org/10.5772/53910.

6 Kador PF, Wyman M. Asteroid hyalosis: pathogenesis and prospects for prevention. Eye (Lond). 2008 Oct;22(10):1278-85. 


\section{Case Reports in Ophthalmology}

\begin{tabular}{l|l}
\hline DOI: $10.1159 / 000508065$ & (c) 2020 The Author(s). Published by S. Karger AG, Basel
\end{tabular}
www.karger.com/cop

Yepez et al.: Apolipoprotein Al-Derived Vitreous Amyloidosis: An Elusive Diagnosis

7 Yu S, Xu Y, Liang X. Unusual Vitreous Opacity in a Chinese Patient. JAMA Ophthalmol. 2019 Oct;137(12):1454.

8 Li MD, Xu HY, Ye JJ, Zhao C. A Case of Primary Vitreous Retinal Lymphoma. Chin Med J (Engl). 2018 Jan;131(1):113-4.

9 Williams JG, Edward DP, Tessler HH, Persing DH, Mitchell PS, Goldstein DA. Ocular manifestations of Whipple disease: an atypical presentation. Arch Ophthalmol. 1998 Sep;116(9):1232-4.

10 Hitchings RA, Tripathi RC. Vitreous opacities in primary amyloid disease. A clinical, histochemical, and ultrastructural report. Br J Ophthalmol. 1976 Jan;60(1):41-54.

11 Doft BH, Machemer R, Skinner M, Buettner H, Clarkson J, Crock J, et al. Pars plana vitrectomy for vitreous amyloidosis. Ophthalmology. 1987 Jun;94(6):607-11.

12 Schneider T, Moos V, Loddenkemper C, Marth T, Fenollar F, Raoult D. Whipple's disease: new aspects of pathogenesis and treatment. Lancet Infect Dis. 2008 Mar;8(3):179-90.

13 Touitou V, Fenollar F, Cassoux N, Merle-Beral H, LeHoang P, Amoura Z, et al. Ocular Whipple's disease: therapeutic strategy and long-term follow-up. Ophthalmology. 2012 Jul;119(7):1465-9.

14 Venkatesh P, Selvan H, Singh SB, Gupta D, Kashyap S, Temkar S, et al. Vitreous Amyloidosis: Ocular, Systemic, and Genetic Insights. Ophthalmology. 2017 Jul;124(7):1014-22.

15 Seca M, Ferreira N, Coelho T. Vitreous Amyloidosis as the Presenting Symptom of Familial Amyloid Polyneuropathy TTR Val30Met in a Portuguese Patient. Case Rep Ophthalmol. 2014 Mar;5(1):92-7.

16 Dunlop AA, Graham SL. Familial amyloidotic polyneuropathy presenting with rubeotic glaucoma. Clin Exp Ophthalmol. 2002 Aug;30(4):300-2.

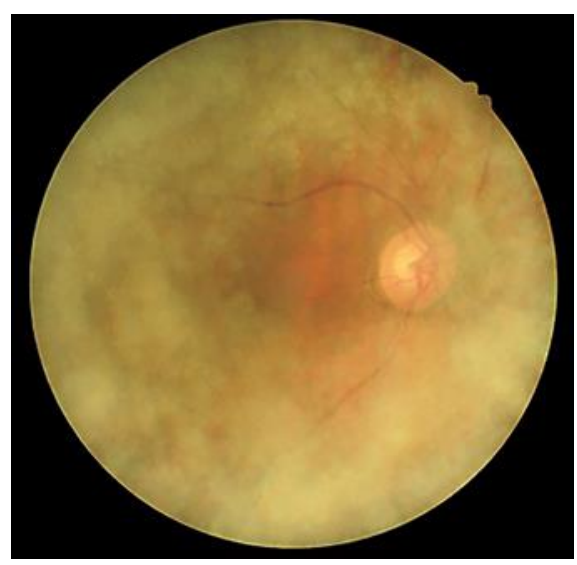

Fig. 1. Right eye at presentation with hazy media and glass-wool-like appearance. 
Case Reports in Ophthalmology
Case Rep Ophthalmol 2020;11:287-292

DOI: $10.1159 / 000508065$

(c) 2020 The Author(s). Published by S. Karger AG, Basel www.karger.com/cop

Yepez et al.: Apolipoprotein Al-Derived Vitreous Amyloidosis: An Elusive Diagnosis

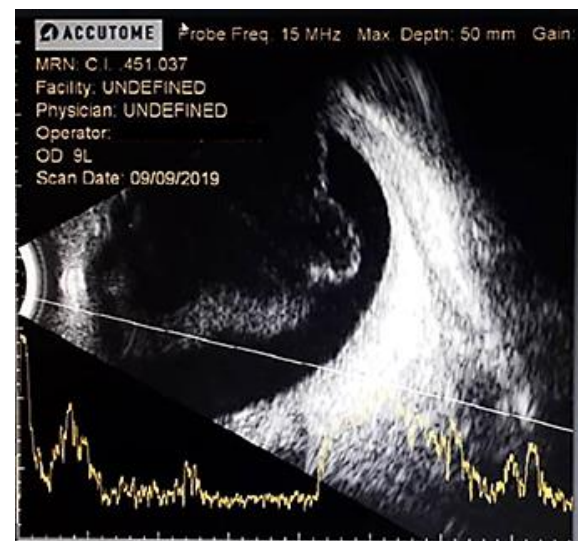

Fig. 2. B-scan ultrasonography showing that the vitreous was full of middle-echo spots and posterior vitreous detachment occurred.

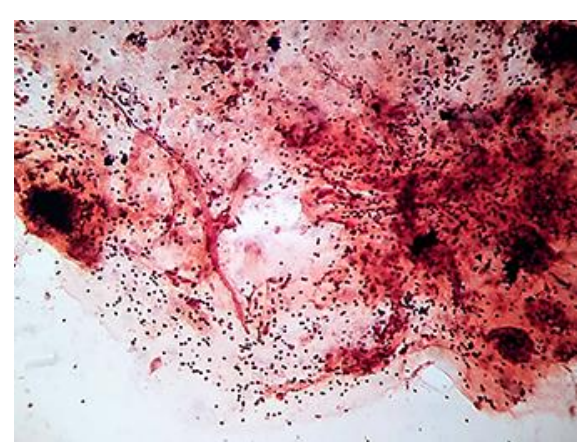

Fig. 3. Vitreous aspirate revealing amorphous acellular material that stained positively with Congo Red. 